Check for updates

Cite this: Mater. Adv., 2022, 3, 2047

Received 9th December 2021, Accepted 5th January 2022

DOI: $10.1039 / \mathrm{d} 1 \mathrm{ma} 01165 k$

rsc.li/materials-advances

\title{
Acetone complexes for high-performance perovskite photovoltaics with reduced nonradiative recombination $\dagger$
}

\author{
Zhen Wang, ${ }^{a}$ Chenguang Yang, ${ }^{a b}$ Yuying Cui, ${ }^{b}$ Li Xie $^{a}$ and Feng Hao (D) *b
}

\begin{abstract}
Solvent engineering has been widely employed in the preparation of high-quality perovskite films for emerging halide perovskite solar cells (PSCs). However, the heavy use of toxic solvents (such as $N$ methyl-2-pyrrolidone (NMP), N,N-dimethylformamide (DMF), etc.) has caused critical concerns for health and the environment. Herein, a greener solvent acetone was applied to partially replace DMF and NMP for depositing high-quality perovskite thin films. During the film deposition, an acetone-MAI-Pbl 2 intermediate was formed to modulate the crystallization process and reduce the grain boundary gaps to achieve high quality perovskite films. The results of photoluminescence spectroscopy, transient photovoltage decay, and Mott-Schottky analysis indicated that this solvent engineering with acetone enabled suppressed trap-assisted nonradiative recombination and facilitated the charge extraction in the corresponding PSC devices. Consequently, the target devices achieved a power conversion efficiency (PCE) of $19.45 \%$, and the open-circuit voltage was enhanced by $70 \mathrm{mV}$ due to the reduced nonradiative recombination. This work provides an idea to alleviate the toxicity of processing solvents that hinders the mass production of PSCs.
\end{abstract}

\section{Introduction}

Perovskite solar cells (PSCs) are attractive candidates for nextgeneration photovoltaic technology due to their remarkable efficiencies and low-cost fabrication process. ${ }^{1}$ PSCs have achieved a certified power conversion efficiency (PCE) record of $25.5 \%$, which is attributed to the outstanding properties of perovskite semiconductors, such as high defect tolerance, low exciton binding energy, long diffusion length, strong optical absorption, and ambipolar charge transport..$^{2-7}$ By means of a low-temperature solution process, perovskite films with low trap density and high crystallinity can be obtained owing to the low activation barrier for crystallization. ${ }^{8,9}$ The one-step spin coating method is one of the most common deposition methods for preparing high-efficiency PSC devices by virtue of its simplicity and scalability. ${ }^{10,11}$

The solution chemistry of perovskite precursors has a strong influence on the crystallization dynamics. ${ }^{12,13}$ The growth kinetics of perovskite crystals critically depends on the solution

\footnotetext{
${ }^{a}$ Faculty of Printing, Packaging and Digital Media Technology, Xi'an University of Technology, Xi'an, 710054, China. E-mail: haofeng@uestc.edu.cn

${ }^{b}$ School of Materials and Energy, University of Electronic Science and Technology of China, Chengdu 611731, China

$\dagger$ Electronic supplementary information (ESI) available. See DOI: 10.1039/ d1ma01165k
}

of colloidal precursors with $\mathrm{PbX}_{n}$ complexes. ${ }^{14,15}$ The colloids can serve as nucleation centers, which are further organized on the substrate forming a solid intermediate phase. ${ }^{16}$ Their structure and stability determine the size and optoelectronic quality of the generated perovskite particles. ${ }^{17}$ In general, the stability of solvent-induced intermediates is closely associated with their coordination ability with $\mathrm{PbI}_{2} \cdot{ }^{18}$ Polar aprotic solvents, such as $N, N$-dimethylformamide (DMF), dimethyl sulfoxide (DMSO), N,N-dimethylacetamide (DMAC), and $N$ methyl-2-pyrrolidone (NMP), are widely used to form intermediates. ${ }^{19-24}$

However, DMF, DMSO, DMCA and NMP are highly toxic and environmentally hazardous, and are widely utilized in most high-performance PSC devices currently. ${ }^{25-28} \mathrm{~A}$ crucial factor limiting the large-scale production of PSCs is the massive use of these toxic solvents. ${ }^{29-31}$ Recently, some attempts have been made to replace the toxic solvents with less toxic $\gamma$ butyrolactone (GBL) and acetonitrile (ACN), although sometimes it is accompanied by the compromise of the device performance. $^{32,33}$ Ramadan et al. fabricated perovskite films which were deposited from ACN solvent only with a PCE of $18.5 \%{ }^{34}$ Huang et al. applied a solvent mixture of GBL and DMSO to form efficient PSCs with a PCE of $17.02 \%$ in an ambient environment. ${ }^{35}$ On the way to green production of PSCs, it is crucial and urgent to replace the toxic solvents with green ones. ${ }^{36-38}$ 
Acetone is a non-toxic, Lewis base solvent with high volatility and low boiling point. Zhang et al. used acetone to assist the low-temperature crystallization of $\mathrm{CsPbI}_{2} \mathrm{Br}$ perovskite films. The addition of acetone improved the strength of the leadLewis base interaction and the wettability of the perovskite precursors. ${ }^{39}$ This demonstrated that the introduction of environmentally-friendly solvent acetone is conducive to forming high-quality perovskite films. However, the specific interaction between acetone and perovskite is poorly investigated and not yet understood.

Herein, a solvent mixture of acetone, DMF, and NMP is applied for the deposition of methylammonium lead iodide $\left(\mathrm{MAPbI}_{3}\right)$ perovskite films. The interaction between acetone and perovskite was systematically probed by Fourier transform infrared spectroscopy (FT-IR) and X-ray diffraction (XRD). It was revealed that the addition of acetone can form acetone-MAI$\mathrm{PbI}_{2}$ complexes to regulate the crystallization process and reduce the grain boundary gaps, resulting in the formation of high-quality perovskite films. A series of carrier dynamic characterization tests further disclosed that the formation of acetone complexes could not only inhibit the nonradiative recombination but also facilitate the charge extraction. With these effects, the PCE and the open-circuit voltage $\left(V_{\text {oc }}\right)$ of the corresponding devices were significantly improved. Meanwhile, the target device also showed improved humidity stability owing to the high hydrophobicity of the as-prepared perovskite film.

\section{Results and discussion}

The precursor solution was prepared by replacing some of the toxic solvent with acetone. The corresponding environmental and health impacts of different solvents are listed in Table S1 (ESI $\dagger$ ). Compared with DMF and NMP, acetone shows better environmental friendliness and lower health damage. The control and target were denoted by mixing acetone and a solvent mixture (NMP:DMF $=9: 8(\mathrm{v}: \mathrm{v})$ ) at volume ratios of $0: 300$ and $50: 250$, respectively. Then it was spin-coated on a $\mathrm{NiO}_{x}$ substrate to form the perovskite layer. X-ray diffraction (XRD) measurements were performed to identify the crystalline phase for the target and control films, as shown in Fig. 1a. It was noted that a new crystalline peak emerged at $10.4^{\circ}$ for the perovskite film with acetone. It was conjectured that this peak was ascribed to the complexes of acetone, $\mathrm{PbI}_{2}$, and MAI. To verify this speculation, the UV-Vis absorption spectra of $\mathrm{PbI}_{2}$, MAI, and equivalent $\mathrm{PbI}_{2}$ and MAI dissolved in acetone were collected, as shown in Fig. 1b. A sharp peak at $324 \mathrm{~nm}$ was assigned for MAI absorption in acetone solution and a broader peak at $339 \mathrm{~nm}$ was ascribed for $\mathrm{PbI}_{2}$ absorption in acetone solution. In particular, a new absorption peak at $374 \mathrm{~nm}$ presented in the solution with equivalent $\mathrm{PbI}_{2}$ and MAI dissolved in acetone. This indicated that this emerged absorption peak can be attributed to a new complex formed by acetone with MAI and $\mathrm{PbI}_{2}$. Afterward, a supersaturated solution was prepared by dissolving an equimolar ratio of $\mathrm{PbI}_{2}$ and MAI in
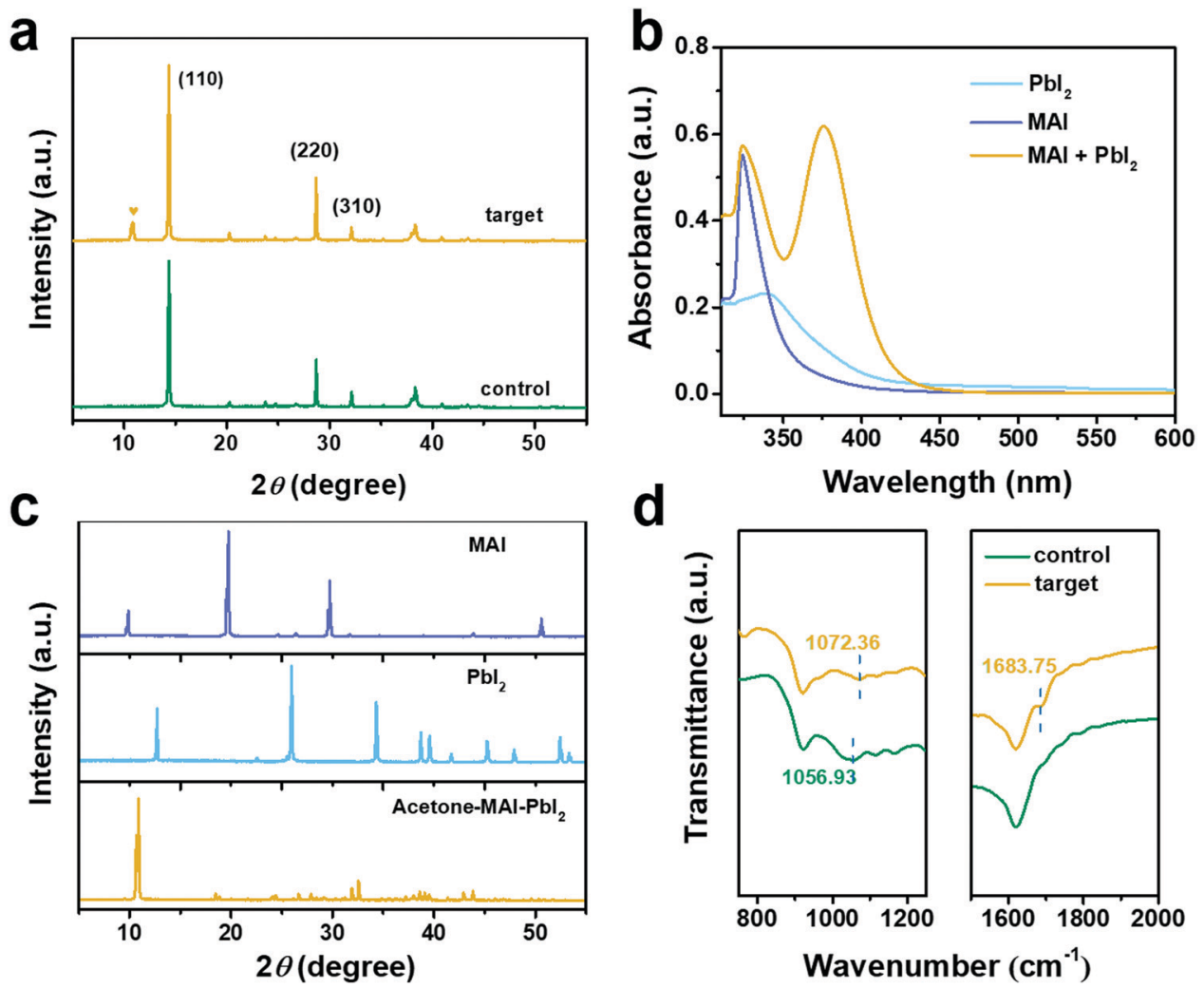

d

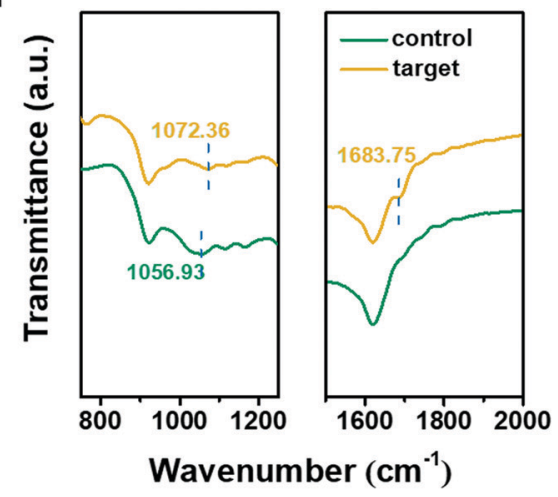

Fig. 1 (a) XRD spectra of the control and target perovskite films. (b) UV-Vis absorbance spectra of $\mathrm{PbI}_{2}, \mathrm{MAI}$, and MAI-Pbl 2 dissolved in acetone. (c) XRD spectra of the acetone-MAI-Pbl 2 complex powder, $\mathrm{Pbl}_{2}$ powder, and MAI powder. (d) The FT-IR spectra of the control and target perovskite films. 
acetone, and then dried into a powder. The XRD patterns of acetone-MAI- $\mathrm{PbI}_{2}, \mathrm{PbI}_{2}$, and MAI powder are exhibited in Fig. 1c, respectively. The peak of acetone-MAI-PbI 2 powder cannot be assigned in the existing database, thus confirming the formation of acetone complexes with $\mathrm{PbI}_{2}$ and MAI (Fig. S4, ESI $\dagger$ ). As shown in Fig. 1c, the acetone-MAI-PbI ${ }_{2}$ powder exhibited a characteristic peak at $10.4^{\circ}$, which is consistent with the extra XRD peak in the target perovskite film (Fig. 1a). The presence of the acetone-MAI- $\mathrm{PbI}_{2}$ complex is further confirmed from the Fourier transform infrared spectroscopy (FT-IR) spectra. As shown in Fig. 1d, compared to the control perovskite film, the target film showed an additional peak at $1683 \mathrm{~cm}^{-1}$, which is ascribed to the $\mathrm{C}=\mathrm{O}$ stretching of acetone. ${ }^{40}$ Similarly, the stretching vibration peak of the $\mathrm{C}-\mathrm{N}$ bond at $1056 \mathrm{~cm}^{-1}$ of the control film shifted to $1071 \mathrm{~cm}^{-1}$ for the target film owing to the coordination between $\mathrm{N}$ and the carbonyl of acetone. ${ }^{41}$ Therefore, it was confirmed that the acetone-MAI- $\mathrm{PbI}_{2}$ complexes were formed by the coordination reaction between acetone with $\mathrm{MAI}$ and $\mathrm{PbI}_{2}$. Moreover, the carbonyl of acetone interacts with the lead ion in $\mathrm{PbI}_{2},{ }^{39}$ while the carbonyl of acetone interacts with both $\mathrm{N}$ and $\mathrm{Pb}$ ions in the acetone-MAI- $\mathrm{PbI}_{2}$ complex. The schematic diagram of the acetone-MAI-PbI ${ }_{2}$ complex is shown in Fig. S5 (ESI $\dagger$ ).

Since the acetone-MAI-PbI ${ }_{2}$ complexes are presented in the precursor solution, it is noteworthy to explore the influences of the complexes on the crystallization process of the perovskite films. XRD spectra of the perovskite films were collected with different annealing times. The diffraction intensity at the (110),
(220), and (310) crystal plane of the control and target perovskite films was significantly enhanced with increasing the annealing time, as shown in Fig. 2a and b. Moreover, the diffraction intensity of the peak at $10.4^{\circ}$ gradually diminished during the annealing process for the target film. This indicated that the acetone-MAI$\mathrm{PbI}_{2}$ complex was in decline with the increase of the annealing time, which may affect the crystallization process of the perovskite film. Fig. 2c and d show the scanning electron microscopy (SEM) images for the control and target perovskite films. The target film with acetone showed reduced grain size and more compact boundaries. The average grain size of the target film with acetone was around $135 \mathrm{~nm}$, while the grain size averaged at $216 \mathrm{~nm}$ for the control perovskite film (Fig. S6, ESI $\dagger$ ). The formation of the acetone-MAI$\mathrm{PbI}_{2}$ complexes in the precursor film leads to an increased number of nucleation sites and thus reduced the grain size of the target perovskite film.

Inverted PSCs with $\mathrm{FTO} / \mathrm{NiO}_{x} /$ perovskite $/ \mathrm{PC}_{61} \mathrm{BM} / \mathrm{PEI} / \mathrm{Ag}$ structure were assembled to explore the role of the intermediates on the photovoltaic performance. The current densityvoltage $(J-V)$ curves were collected under simulated AM $1.5 \mathrm{G}$ $\left(100 \mathrm{~mW} \mathrm{~cm}^{-2}\right.$ ) solar illumination (Fig. S7 and Table S2, ESI $\dagger$ ). The volume ratio of acetone to NMP/DMF mixture was varied from $0: 300$ to $60: 240$, and the best performance was attained at the optimal ratio of $50: 250$. The specific properties of the PSC devices are presented in Fig. 3a and Table 1. The target device exhibited a PCE of $19.45 \%$, with a short-circuit photocurrent density $\left(J_{\mathrm{sc}}\right)$ of $22.01 \mathrm{~mA} \mathrm{~cm} \mathrm{~cm}^{-2}$, an open-circuit voltage $\left(V_{\mathrm{oc}}\right)$ of $1.12 \mathrm{~V}$, and a fill factor $(\mathrm{FF})$ of $79.02 \%$, respectively. While for

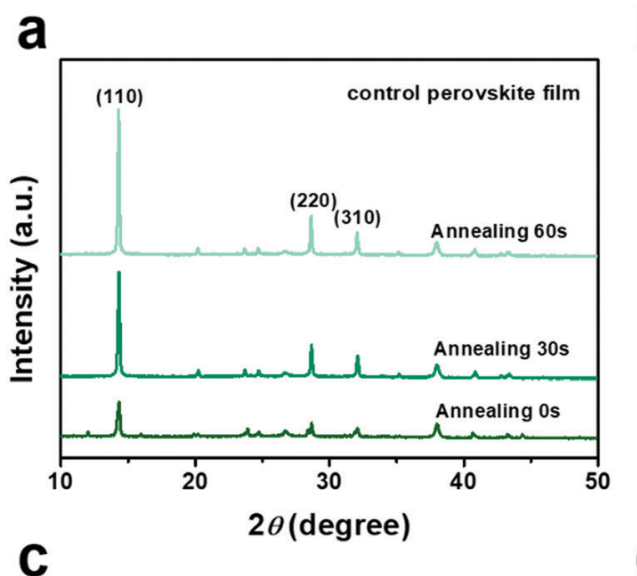

b
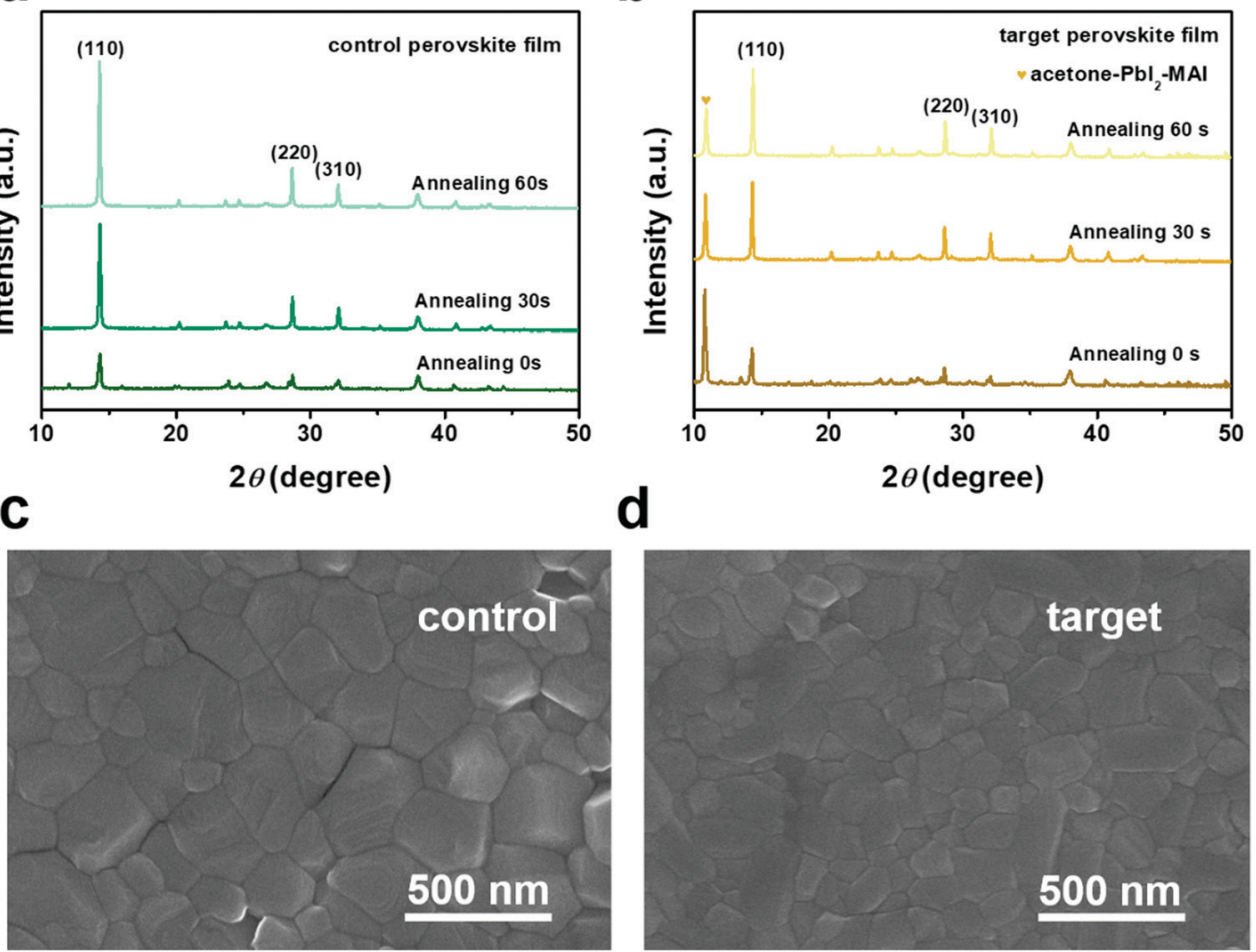

Fig. 2 XRD profiles for the control (a) and target (b) films with different annealing times. Top view SEM of the control perovskite film (c) and the target film (d). 

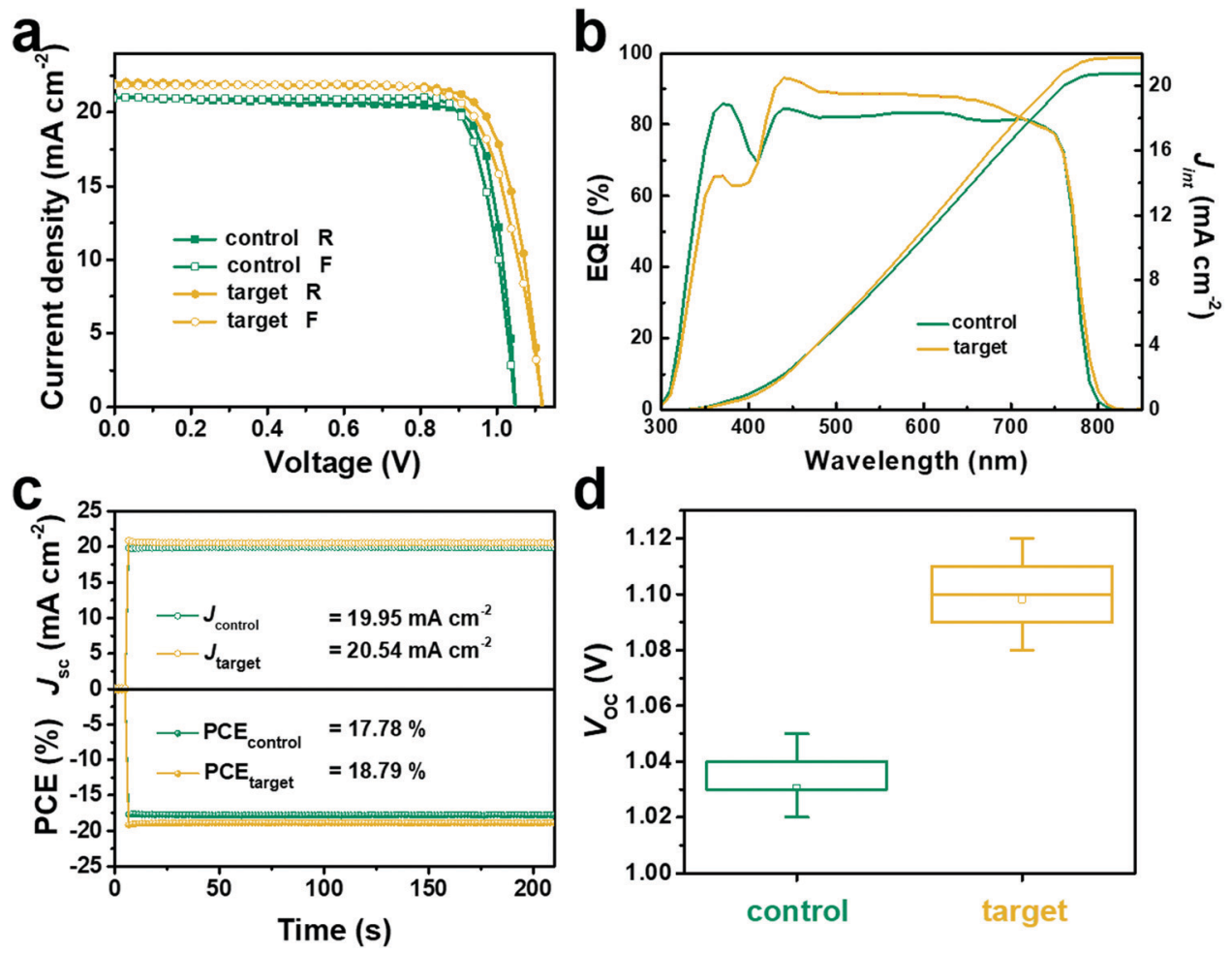

Fig. 3 (a) $J-V$ curves of the control and target devices. (b) IPCE spectra and the corresponding integrated photocurrent density ( $\left.J_{\text {int }}\right)$ for the control and target devices. (c) The steady-state power output and photocurrent of the devices. (d) Statistical distributions of $V_{\text {oc }}$ for a batch of 25 independent devices.

Table 1 Photovoltaic parameters for the control and target devices

\begin{tabular}{|c|c|c|c|c|c|}
\hline & & $J_{\mathrm{sc}}\left(\mathrm{mA} \mathrm{cm}^{-2}\right)$ & $V_{\mathrm{oc}}(\mathrm{V})$ & $\mathrm{FF}(\%)$ & PCE (\%) \\
\hline \multirow[t]{3}{*}{ Control } & Reverse & 21.04 & 1.05 & 82.14 & 18.12 \\
\hline & Forward & 20.99 & 1.05 & 81.95 & 18.02 \\
\hline & Average & $21.02 \pm 0.02$ & $1.05 \pm 0.01$ & $82.04 \pm 0.10$ & $18.07 \pm 0.05$ \\
\hline \multirow[t]{3}{*}{ Target } & Reverse & 22.01 & 1.12 & 79.02 & 19.45 \\
\hline & Forward & 21.84 & 1.12 & 76.43 & 18.71 \\
\hline & Average & $21.93 \pm 0.09$ & $1.12 \pm 0.01$ & $77.73 \pm 1.29$ & $19.08 \pm 0.37$ \\
\hline
\end{tabular}

the control device, it only achieved a PCE of $18.12 \%$, a $J_{\mathrm{sc}}$ of $21.04 \mathrm{~mA} \mathrm{~cm}{ }^{-2}$, a $V_{\text {oc }}$ of $1.05 \mathrm{~V}$, and a $\mathrm{FF}$ of $82.14 \%$. The performance enhancement of the target device was manifested in the enlargement of the $V_{\mathrm{oc}}$ and $J_{\mathrm{sc}}$ value. The integrated photocurrent densities $\left(J_{\text {int }}\right)$ were interpreted from the incident photon-to-electron conversion efficiency (IPCE) spectra, which also can reflect the accuracy of $J_{\mathrm{sc}}$. The target devices generated a $J_{\text {int }}$ of $21.71 \mathrm{~mA} \mathrm{~cm} \mathrm{~cm}^{-2}$ compared to the control devices with $20.70 \mathrm{~mA} \mathrm{~cm}^{-2}$, both of which were highly in accordance with the $J_{\mathrm{sc}}$ value, as shown in Fig. 3b. At the maximum power point (MPP), both the stabilized current density and the steady-state power output were monitored in $220 \mathrm{~s}$ (Fig. 3c). The control device exhibited a steady $J_{\mathrm{sc}}$ of $19.95 \mathrm{~mA} \mathrm{~cm} \mathrm{~cm}^{-2}$ and a PCE of $17.78 \%$ at the MPP of $0.90 \mathrm{~V}$, while the target device showed a steady $J_{\mathrm{sc}}$ of $20.54 \mathrm{~mA} \mathrm{~cm}^{-2}$ and a PCE of $18.79 \%$ at the MPP of $0.94 \mathrm{~V}$. A batch of 25 independent devices for the control and target experiment were prepared to further confirm the repeatability of the photovoltaic performance. The target devices exhibited a significantly higher $V_{\mathrm{oc}}$ and PCE than the control devices (Fig. 3d and Fig. S8, ESI $\dagger$ ). The improvement of $V_{\mathrm{oc}}$ and $J_{\mathrm{sc}}$ may be related to the high-quality perovskite film crystallized from the acetone-MAI-PbI ${ }_{2}$ complex.

Ultraviolet and visible (UV-Vis) spectra of the perovskite films were collected in Fig. 4a. Typically, the target film showed slightly enhanced absorption at the wavelength of 550-750 nm, which was mainly related to the more compact morphology compared to the control film, as presented in Fig. 2. Moreover, based on the steady-state photoluminescence (PL) spectra, it showed that the PL intensity of the target film was enhanced about 10 times compared to the control one (Fig. 4b), thus indicating the superior crystalline quality for the target film. ${ }^{42,43}$ Furthermore, transient photocurrent decay (TPC) was measured to monitor the charge transport in the device. As shown in Fig. 4c, it demonstrated that the photocurrent decay time of the target device $(0.69 \mu \mathrm{s})$ was prominently shorter than that of the control one $(1.57 \mu \mathrm{s})$. It suggested that faster charge transport occurred in the target devices. ${ }^{44}$ Besides, transient photovoltage decay (TPV) was further measured to investigate the charge recombination lifetime. It showed that the target device reached up to $12.46 \mu$ s compared to $5.38 \mu$ s of the control one, which was presented in Fig. $4 \mathrm{~d}$. This suggested that the charge recombination in the target device was substantially diminished. ${ }^{45}$

In addition, the $J-V$ property was probed at different light intensities (1-100 $\mathrm{mW} \mathrm{\textrm {cm } ^ { - 2 }}$ ) to further investigate the charge 
a
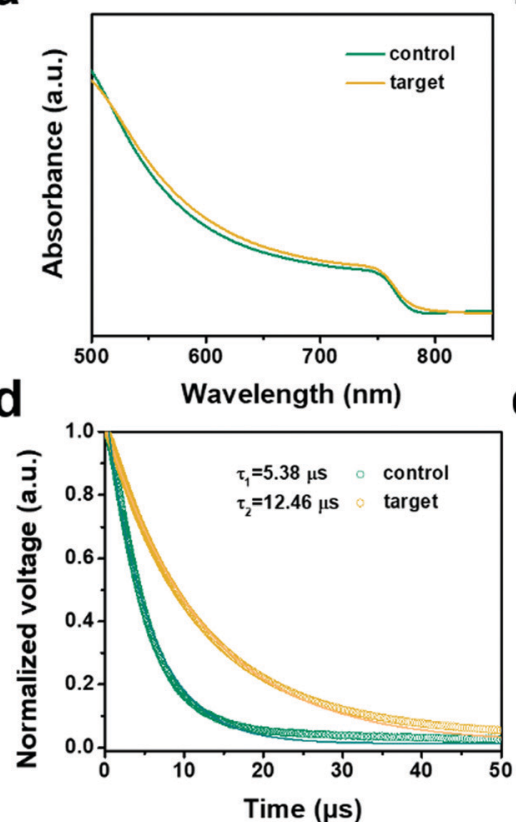

b
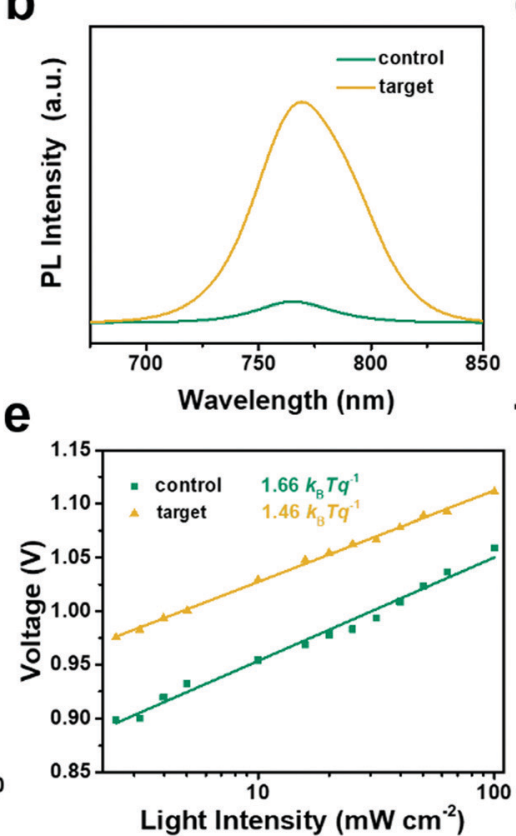
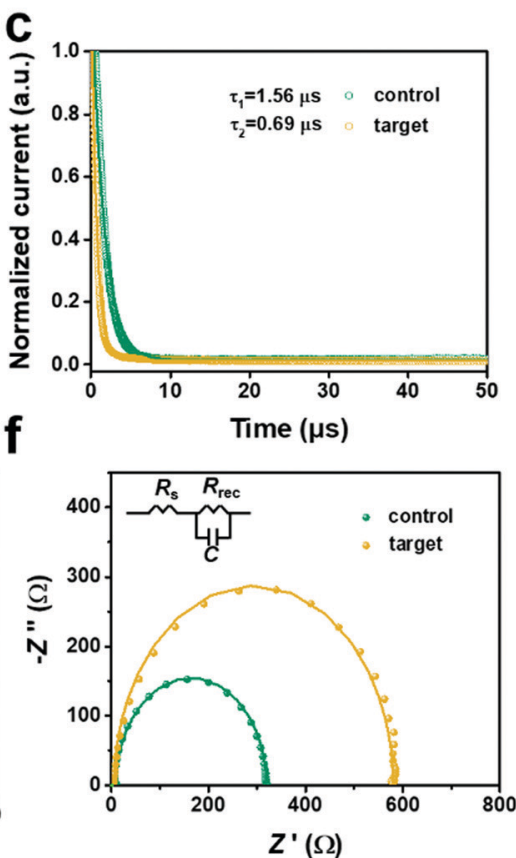

Fig. 4 (a) UV-Vis absorption and (b) steady-state PL spectra for the control and target film, (c) normalized TPC and (d) TPV, (e) $V_{\text {oc }}$ dependence on the light intensity, (f) Nyquist plots for the control and target devices. The inset of (f) shows the corresponding equivalent circuit for the fitting.

recombination kinetics. The curves of $V_{\mathrm{oc}}$ versus light intensity are shown in Fig. 4e. Notably, a slope of $1.46 k_{\mathrm{B}} T q^{-1}$ was acquired for the target device. While a slope of $1.66 k_{\mathrm{B}} T q^{-1}$ was attained for the control device. Consequently, the slope of
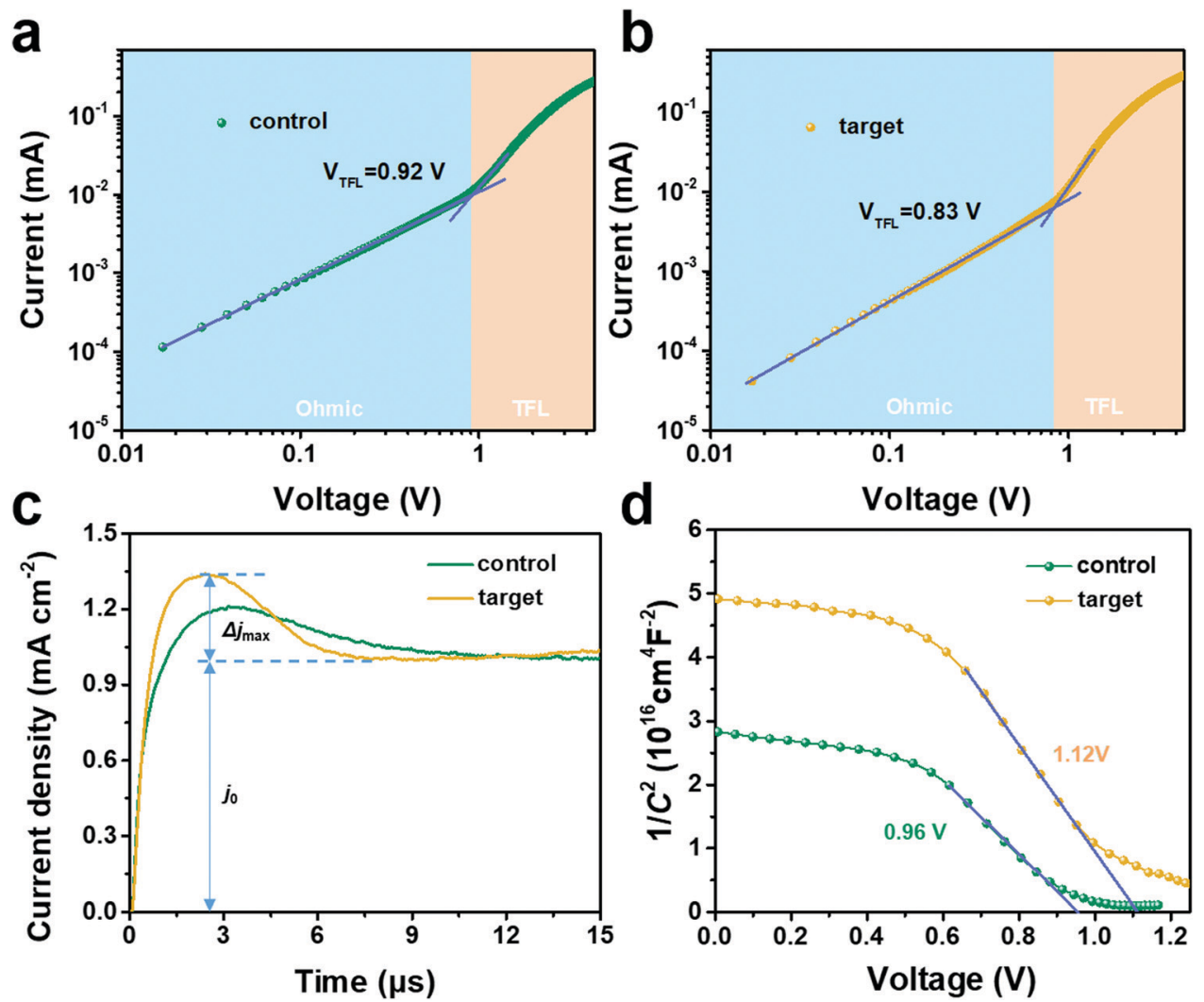

Fig. 5 SCLC plots of electron-only devices for (a) the control and (b) target devices with a structure of FTO/SnO $2 /$ perovskite/PC $_{61} \mathrm{BM} / \mathrm{Ag}_{\text {; }}$ (c) photoCELIV current transients and (d) Mott-Schottky plots at $20 \mathrm{kHz}$ under dark conditions for the control and target devices. 
the target device was more closer to 1, thus reflecting the suppressed Shockley-Read-Hall (SRH) recombination in the target device. ${ }^{46}$ Finally, the charge transport properties of the PSCs were elucidated by electrochemical impedance spectroscopy (EIS). Fig. 4f and Table S3 (ESI $\dagger$ ) depicted the Nyquist plots under dark conditions. The target device displayed a higher recombination resistance $\left(R_{\text {rec }}\right)$ of $575 \Omega$ compared to the $310 \Omega$ for the control device, which implied that the target device was more restrained in charge recombination than the control device. ${ }^{47}$ A slight reduced series resistance $\left(R_{\mathrm{S}}\right)$ indicated better crystalline quality in the target device. $^{48}$

Additionally, the trap state density $\left(N_{\mathrm{t}}\right)$ can be evaluated based on the space charge-limited current (SCLC), ${ }^{49}$ which can be determined via the trap-filled limit voltage $\left(V_{\mathrm{TFL}}\right)$ according to the equation:

$$
N_{\mathrm{t}}=\frac{2 \varepsilon \varepsilon_{0} V_{\mathrm{TFL}}}{e L^{2}}
$$

Where $\varepsilon$ is the relative dielectric constant of $\mathrm{MAPbI}_{3}, \varepsilon_{0}$ is the vacuum permittivity, $\mathrm{L}$ is the thickness of the perovskite film ( $L=420 \mathrm{~nm}$ ) and $e$ is the elementary charge of an electron, respectively. ${ }^{47}$ An electron-only device with an $\mathrm{FTO} / \mathrm{SnO}_{2} /$ perovskite/ $\mathrm{PC}_{61} \mathrm{BM} / \mathrm{Ag}$ structure was used to measure the $V_{\mathrm{TFL}}$ in the dark. As shown in Fig. $5 \mathrm{a}$ and b, the $V_{\text {TFL }}$ value of the target device was $0.83 \mathrm{~V}$, and it was a bit lower than that of the control device $(0.92 \mathrm{~V})$. Therefore, the target film exhibited a lower $N_{\mathrm{t}}$ value of $3.64 \times 10^{16} \mathrm{~cm}^{-3}$ compared to that of the control device $\left(4.03 \times 10^{16} \mathrm{~cm}^{-3}\right)$. The decreased defect density indicated that the acetone-MAI-PbI ${ }_{2}$ complex could effectively passivate defects of perovskite films, which was consistent with the PL results. ${ }^{50}$ The carrier mobility was determined from the photo-generated carrier extraction via the linearly increasing voltage (Photo-CELIV) technique. ${ }^{51,52}$ The electron mobility $\left(\mu_{\mathrm{e}}\right)$ can be described as follows:

$$
\mu_{\mathrm{e}}=\frac{2 d^{2}}{3 A t_{\max }^{2}\left[1+0.36 \frac{\Delta j}{j_{0}}\right]}
$$

where $\Delta j, j_{0}, t_{\max }, d$, and $A$ correspond to the maximum current, displacement current, time at the maximum $\Delta j$ of the extraction peak, thickness of the device, and voltage rise speed, respectively. Using an electron-only device with (FTO/SnO $/$ perovskite/ $\mathrm{PC}_{61} \mathrm{BM} / \mathrm{Ag}$ ) structure, the target device showed a $\mu_{\mathrm{e}}$ of $1.49 \times$ $10^{-3} \mathrm{~cm}^{2} \mathrm{~V}^{-1} \mathrm{~s}^{-1}$, which is larger than that of the control one $\left(9.22 \times 10^{-4} \mathrm{~cm}^{2} \mathrm{~V}^{-1} \mathrm{~s}^{-1}\right)$, as shown in Fig. 5c and Table S4 (ESI $\dagger$ ).

The electronic and doping characteristics of the devices were investigated via Mott-Schottky (M-S) analysis. ${ }^{53}$ Under dark conditions, the junction capacitance is calculated based on the function of bias voltage, as shown in eqn (3):

$$
\frac{1}{C^{2}}=\frac{2}{\varepsilon \varepsilon_{0} q A^{2} N_{\mathrm{d}}}\left(V_{\mathrm{bi}}-V\right)
$$

where $V, \varepsilon, \varepsilon_{0} A, q$ and $C$ are the applied potential, the relative dielectric constant, the vacuum permittivity, the active area of the device, the elementary charge and the measured capacitance, respectively. ${ }^{54}$ The value of doping density of the donor $\left(N_{\mathrm{d}}\right)$ and built-in potential $\left(V_{\mathrm{bi}}\right)$ are obtained from the $\mathrm{M}-\mathrm{S}$ curves. $V_{\text {bi }}$ could be specified as an intercept with the $X$-axis of the linear region in the Mott-Schottky diagram. Notably, as shown in Fig. 5d, the $V_{\text {bi }}$ of the control devices enhanced from $0.96 \mathrm{~V}$ to $1.12 \mathrm{~V}$ of the target devices, which is in accordance with the increased $V_{\text {oc }}{ }^{55}$ As we know, one of the crucial factors limiting the large-scale application of PSCs is the operation stability. ${ }^{56}$ Herein, the performance stability of the devices under humidity conditions was investigated. As shown in Fig. S9 (ESI $\dagger$ ), the unencapsulated target devices exhibited better stability than the control devices at $20 \%$ relative humidity and $25{ }^{\circ} \mathrm{C}$, maintaining $80 \%$ of the original PCE after more than 500 hours. The improvement in stability is mainly due to the improvement of the film quality and reduction in trap density. ${ }^{57}$ Fig. S10 (ESI $\dagger$ ) presents the water contact angle of the perovskite films. The target film showed a water contact angle of $57.6^{\circ}$, higher than that of the control film $\left(40.8^{\circ}\right)$, which supported that the acetone complex could enhance the hydrophobicity of the perovskite film.

\section{Conclusions}

In summary, high-quality perovskite thin films were deposited using the eco-friendly solvent acetone to replace some of the toxic NMP/DMF as the solvent. It demonstrated that the formation of acetone-MAI-PbI ${ }_{2}$ complexes could obviously improve the quality of the perovskite thin films by modulating the crystallization process. The as-prepared perovskite films exhibited reduced grain size and grain boundary gaps, with a more compact morphology. The PL, TPC, TPV, and light intensity dependence results of $V_{\mathrm{oc}}$ demonstrated that the target films were able to suppress the trap-assisted nonradiative recombination. Also, the built-in potential $\left(V_{\mathrm{bi}}\right)$ was enhanced for the target device, which can serve to increase the charge extraction process. Therefore, the target devices exhibited favorable improvement in $V_{\mathrm{oc}}$ and $J_{\mathrm{sc}}$, and the inverted $\mathrm{MAPbI}_{3}$ PSCs exhibited a substantial improvement of the PCE (19.45\%). The combination of improved hydrophobicity and decreased trap density further contributed to better stability in a humid environment. The green solvent acetone is expected to be extendable to other perovskite compositions, which provides a greener route towards the environmentally friendly manufacturing of PSCs.

\section{Conflicts of interest}

The authors declare that they have no conflict of interest.

\section{Acknowledgements}

This work was financially supported by the National Natural Science Foundation of China NSFC (51702038 and 52102145), the Xi'an Science and Technology Bureau Planning project 
(Grant No. 21XJZZ0054), the Postdoctoral Science Foundation of Shaanxi Province (Grant No. 2018BSHEDZZ101), the Science and Technology Bureau of Beilin District, Xi'an (Grant No. GX2035), the Key Project of the Science \& Technology Department of Sichuan Province (2020YFG0061) and the Recruitment Program for Young Professionals.

\section{References}

1 B. Wilk, S. Öz, E. Radicchi, F. Ünlü, T. Ahmad, A. P. Herman, F. Nunzi, S. Mathur, R. Kudrawiec and K. Wojciechowski, Green Solvent-Based Perovskite Precursor Development for Ink-Jet Printed Flexible Solar Cells, ACS Sustainable Chem. Eng., 2021, 9, 3920-3930.

2 H. J. Snaith, Perovskites: The Emergence of a New Era for Low-Cost, High-Efficiency Solar Cells, J. Phys. Chem. Lett., 2013, 4, 3623-3630.

3 Z. Yang, A. Surrente, K. Galkowski, N. Bruyant, D. K. Maude, A. A. Haghighirad, H. J. Snaith, P. Plochocka and R. J. Nicholas, Unraveling the Exciton Binding Energy and the Dielectric Constant in Single-Crystal Methylammonium Lead Triiodide Perovskite, J. Phys. Chem. Lett., 2017, 8, 1851-1855.

4 J. Chen and N. G. Park, Causes and Solutions of Recombination in Perovskite Solar Cells, Adv. Mater., 2019, 31, 1803019.

5 H. Zhang, M. K. Nazeeruddin and W. C. H. Choy, Perovskite Photovoltaics: The Significant Role of Ligands in Film Formation, Passivation, and Stability, Adv. Mater., 2019, 31, 1805702.

6 W. Xu, Y. Gao, W. Ming, F. He, J. Li, X. H. Zhu, F. Kang, J. Li and G. Wei, Suppressing Defects-Induced Nonradiative Recombination for Efficient Perovskite Solar Cells through Green Antisolvent Engineering, Adv. Mater., 2020, 32, 2003965.

7 Best Research-Cell Efficiencies. https:/www.nrel.gov/pv/cellefficiency.html (accessed November 2021).

8 D. T. Moore, H. Sai, K. W. Tan, D. M. Smilgies, W. Zhang, H. J. Snaith, U. Wiesner and L. A. Estroff, Crystallization Kinetics of Organic-Inorganic Trihalide Perovskites and the Role of the Lead Anion in Crystal Growth, J. Am. Chem. Soc., 2015, 137, 2350-2358.

9 J. Huang, Y. Yuan, Y. Shao and Y. Yan, Understanding the Physical Properties of Hybrid Perovskites for Photovoltaic Applications, Nat. Rev. Mater., 2017, 2, 17042.

10 N. J. Jeon, J. H. Noh, W. S. Yang, Y. C. Kim, S. Ryu, J. Seo and S. I. Seok, Compositional Engineering of Perovskite Materials for High-Performance Solar Cells, Nature, 2015, 517, 476-480.

11 G. Zheng, C. Zhu, J. Ma, X. Zhang, G. Tang, R. Li, Y. Chen, L. Li, J. Hu, J. Hong, Q. Chen, X. Gao and H. Zhou, Manipulation of Facet Orientation in Hybrid Perovskite Polycrystalline Films by Cation Cascade, Nat. Commun., 2018, 9, 2793.

12 N. J. Jeon, J. H. Noh, Y. C. Kim, W. S. Yang, S. Ryu and S. I. Seok, Solvent Engineering for High-Performance Inorganic-Organic Hybrid Perovskite Solar Cells, Nat. Mater., 2014, 13, 897-903.
13 J. Zhang, L. Zhang, X. Li, X. Zhu, J. Yu and K. Fan, Binary Solvent Engineering for High-Performance TwoDimensional Perovskite Solar Cells, ACS Sustainable Chem. Eng., 2019, 7, 3487-3495.

14 K. Yan, M. Long, T. Zhang, Z. Wei, H. Chen, S. Yang and J. Xu, Hybrid Halide Perovskite Solar Cell Precursors: Colloidal Chemistry and Coordination Engineering Behind Device Processing for High Efficiency, J. Am. Chem. Soc., 2015, 137, 4460-4468.

15 E. Radicchi, E. Mosconi, F. Elisei, F. Nunzi and F. De Angelis, Understanding the Solution Chemistry of Lead Halide Perovskites Precursors, ACS Appl. Energy Mater., 2019, 2, 3400-3409.

16 N. S. Dutta, N. K. Noel and C. B. Arnold, Crystalline Nature of Colloids in Methylammonium Lead Halide Perovskite Precursor Inks Revealed by Cryo-Electron Microscopy, J. Phys. Chem. Lett., 2020, 11, 5980-5986.

17 B. Li, M. Li, C. Fei, G. Cao and J. Tian, Colloidal Engineering for Monolayer $\mathrm{CH}_{3} \mathrm{NH}_{3} \mathrm{PbI}_{3}$ Films Toward High Performance Perovskite Solar Cells, J. Mater. Chem. A, 2017, 5, 24168-24177.

18 Z. Li, Y. Sun, H. Yao, J. Zhao, Q. Wang, L. Ding and Z. Jin, Intermediates Transformation for Efficient Perovskite Solar Cells, J. Energy Chem., 2021, 52, 102-114.

19 N. Ahn, D. Y. Son, I. H. Jang, S. M. Kang, M. Choi and N. G. Park, Highly Reproducible Perovskite Solar Cells with Average Efficiency of $18.3 \%$ and Best Efficiency of $19.7 \%$ Fabricated via Lewis Base Adduct of Lead(II) Iodide, J. Am. Chem. Soc., 2015, 137, 8696-8699.

20 D. Shen, X. Yu, X. Cai, M. Peng, Y. Ma, X. Su, L. Xiao and D. Zou, Understanding The Solvent-Assisted Crystallization Mechanism Inherent In Efficient Organic-Inorganic Halide Perovskite Solar Cells, J. Mater. Chem. A, 2014, 2, 20454-20461.

21 X. Deng, Z. Cao, Y. Yuan, M. Oliver Lam Chee, L. Xie, A. Wang, Y. Xiang, T. Li, P. Dong, L. Ding and F. Hao, Coordination Modulated Crystallization and Defect Passivation in high Quality Perovskite Film for Efficient Solar Cells, Coord. Chem. Rev., 2020, 420, 213408.

22 Y. Jo, K. S. Oh, M. Kim, K. H. Kim, H. Lee, C. W. Lee and D. S. Kim, High Performance of Planar Perovskite Solar Cells Produced from $\mathrm{PbI}_{2}(\mathrm{DMSO})$ and $\mathrm{PbI}_{2}(\mathrm{NMP})$ Complexes by Intramolecular Exchange, Adv. Mater. Interfaces, 2016, 3, 1500768.

23 K. Liao, L. Xie, Y. Cui, S. Wang, C. Li, A. Wang, X. Deng, Y. Xiang, L. Ding and F. Hao, Aqueous Solvent-Regulated Crystallization and Interfacial Modification in Perovskite Solar Cells With Enhanced Stability and Performance, J. Power Sources, 2020, 471, 228447.

24 S. Wang, J. Hu, A. Wang, Y. Cui, B. Chen, X. Niu and F. Hao, Facile Lattice Tensile Strain Compensation in Mixed-Cation Halide Perovskite Solar Cells, J. Energy Chem., 2022, 66, 422-428.

25 L. Xie, X. Deng, C. Li, Y. Cui, Z. Cao, A. Wang, S. Wang, Y. Chen, Z. Wang, Y. Liu, Q. Bao, L. Ding and F. Hao, Tetrazole Modulated Perovskite Films for Efficient Solar Cells with Improved Moisture Stability, Chem. Eng. J., 2021, 420, 127579. 
26 M. Kim, G.-H. Kim, T. K. Lee, I. W. Choi, H. W. Choi, Y. Jo, Y. J. Yoon, J. W. Kim, J. Lee, D. Huh, H. Lee, S. K. Kwak, J. Y. Kim and D. S. Kim, Methylammonium Chloride Induces Intermediate Phase Stabilization for Efficient Perovskite Solar Cells, Joule, 2019, 3, 2179-2192.

27 J. Li, J. Duan, X. Yang, Y. Duan, P. Yang and Q. Tang, Review on Recent Progress of Lead-Free Halide Perovskites in Optoelectronic Applications, Nano Energy, 2021, 80, 105526.

28 Y. Cui, S. Wang, L. Ding and F. Hao, Green-SolventProcessable Perovskite Solar Cells, Adv. Energy Sustainability Res., 2020, 2, 2000047.

29 T. Bu, L. Wu, X. Liu, X. Yang, P. Zhou, X. Yu, T. Qin, J. Shi, S. Wang, S. Li, Z. Ku, Y. Peng, F. Huang, Q. Meng, Y.-B. Cheng and J. Zhong, Synergic Interface Optimization with Green Solvent Engineering in Mixed Perovskite Solar Cells, Adv. Energy Mater., 2017, 7, 1700576.

30 M. Zhang, D. Xin, X. Zheng, Q. Chen and W.-H. Zhang, Toward Greener Solution Processing of Perovskite Solar Cells, ACS Sustainable Chem. Eng., 2020, 8, 13126-13138.

31 Y. Cui, S. Wang, C. Li, A. Wang, J. Ren, C. Yang, B. Chen, Z. Wang and F. Hao, Eco-Friendly Antisolvent Enabled Inverted $\mathrm{MAPbI}_{3}$ Perovskite Solar Cells with Fill Factors over 84\%, Green Chem., 2021, 23, 3633-3641.

32 L. Li, Y. Chen, Z. Liu, Q. Chen, X. Wang and H. Zhou, The Additive Coordination Effect on Hybrids Perovskite Crystallization and High-Performance Solar Cell, Adv. Mater., 2016, 28, 9862-9868.

33 H. B. Kim, H. Choi, J. Jeong, S. Kim, B. Walker, S. Song and J. Y. Kim, Mixed Solvents for the Optimization of Morphology in Solution-Processed, Inverted-Type Perovskite/Fullerene Hybrid Solar Cells, Nanoscale, 2014, 6, 6679-6683.

34 A. J. Ramadan, N. K. Noel, S. Fearn, N. Young, M. Walker, L. A. Rochford and H. J. Snaith, Unravelling the Improved Electronic and Structural Properties of Methylammonium Lead Iodide Deposited from Acetonitrile, Chem. Mater., 2018, 30, 7737-7743.

35 S. H. Huang, K. Y. Tian, H. C. Huang, C. F. Li, W. C. Chu, K. M. Lee, Y. C. Huang and W. F. Su, Controlling the Morphology and Interface of the Perovskite Layer for Scalable High-Efficiency Solar Cells Fabricated Using Green Solvents and Blade Coating in an Ambient Environment, ACS Appl. Mater. Interfaces, 2020, 12, 26041-26049.

36 G. Giuliano, A. Bonasera, M. Scopelliti, D. Chillura Martino, T. Fiore and B. Pignataro, Boosting the Performance of OneStep Solution-Processed Perovskite Solar Cells Using a Natural Monoterpene Alcohol as a Green Solvent Additive, ACS Appl. Electron. Mater., 2021, 3, 1813-1825.

37 M. Yavari, M. Mazloum-Ardakani, S. Gholipour, M. M. Tavakoli, S.-H. Turren-Cruz, N. Taghavinia, M. Grätzel, A. Hagfeldt and M. Saliba, Greener, Nonhalogenated Solvent Systems for Highly Efficient Perovskite Solar Cells, Adv. Energy Mater., 2018, 8, 1800177.

38 M. Wang, Q. Fu, L. Yan, J. Huang, Q. Ma, M. Humayun, W. Pi, X. Chen, Z. Zheng and W. Luo, Systematic Optimization of Perovskite Solar Cells via Green Solvent Systems, Chem. Eng. J., 2020, 387, 123966.
39 W. Tang, Y. Chen, J. Yang, R. Yuan, Y. Lv, Q. Ma, Y. Wu, P. Zhang and W.-H. Zhang, Acetone-Assisted Precursor Engineering Enables Low-Temperature Fabrication of $\mathrm{CsPbI}_{2} \mathrm{Br}$ Perovskite for Efficient Solar Cells, J. Power Sources, 2021, 482, 228965.

40 Y. Cai, J. Cui, M. Chen, M. Zhang, Y. Han, F. Qian, H. Zhao, S. Yang, Z. Yang, H. Bian, T. Wang, K. Guo, M. Cai, S. Dai, Z. Liu and S. Liu, Multifunctional Enhancement for Highly Stable and Efficient Perovskite Solar Cells, Adv. Funct. Mater., 2020, 31, 2005776.

41 J. Zhu, M. Tang, B. He, K. Shen, W. Zhang, X. Sun, M. Sun, H. Chen, Y. Duan and Q. Tang, Ultraviolet Filtration and Defect Passivation for Efficient and Photostable $\mathrm{CsPbr}_{3}$ Perovskite Solar Cells by Interface Engineering with Ultraviolet Absorber, Chem. Eng. J., 2021, 404, 126548.

42 N. Chen, X. Yi, J. Zhuang, Y. Wei, Y. Zhang, F. Wang, S. Cao, C. Li and J. Wang, An Efficient Trap Passivator for Perovskite Solar Cells: Poly(propylene glycol) bis(2-aminopropyl ether), Nano-Micro Lett., 2020, 12, 177.

43 Y. Zhao, P. Zhu, S. Huang, S. Tan, M. Wang, R. Wang, J. Xue, T. H. Han, S. J. Lee, A. Zhang, T. Huang, P. Cheng, D. Meng, J. W. Lee, J. Marian, J. Zhu and Y. Yang, Molecular Interaction Regulates the Performance and Longevity of Defect Passivation for Metal Halide Perovskite Solar Cells, J. Am. Chem. Soc., 2020, 142, 20071-20079.

44 R. Wang, J. Xue, L. Meng, J.-W. Lee, Z. Zhao, P. Sun, L. Cai, T. Huang, Z. Wang, Z.-K. Wang, Y. Duan, J. L. Yang, S. Tan, Y. Yuan, Y. Huang and Y. Yang, Caffeine Improves the Performance and Thermal Stability of Perovskite Solar Cells, Joule, 2019, 3, 1464-1477.

45 Z. Yao, W. Zhao, S. Chen, Z. Jin and S. F. Liu, Mn Doping of $\mathrm{CsPbI}_{3}$ Film Towards High-Efficiency Solar Cell, ACS Appl. Energy Mater., 2020, 3, 5190-5197.

46 L. Xie, Z. Cao, J. Wang, A. Wang, S. Wang, Y. Cui, Y. Xiang, X. Niu, F. Hao and L. Ding, Improving Energy Level Alignment By Adenine for Efficient and Stable Perovskite Solar Cells, Nano Energy, 2020, 74, 104846.

47 L. Xie, J. Xie, S. Wang, B. Chen, C. Yang, Z. Wang, X. Liu, J. Chen, K. Jia and F. Hao, Fluorinated Oligomer Wrapped Perovskite Crystals for Inverted $\mathrm{MAPbI}_{3}$ Solar Cells with 21\% Efficiency and Enhanced Stability, ACS Appl. Mater. Interfaces, 2021, 13, 26093-26101.

48 X. Deng, Z. Cao, C. Li, S. Wang and F. Hao, Benzotriazole Derivative Inhibits Nonradiative Recombination and Improves the UV-Stability of Inverted $\mathrm{MAPbI}_{3}$ Perovskite Solar Cells, J. Energy Chem., 2022, 65, 592-599.

49 A. A. Zhumekenov, M. I. Saidaminov, M. A. Haque, E. Alarousu, S. P. Sarmah, B. Murali, I. Dursun, X.-H. Miao, A. L. Abdelhady, T. Wu, O. F. Mohammed and O. M. Bakr, Formamidinium Lead Halide Perovskite Crystals with Unprecedented Long Carrier Dynamics and Diffusion Length, ACS Energy Lett., 2016, 1, 32-37.

50 L. Qiu, K. Xing, J. Zhang, Y. Yang, W. Cao, X. Zhou, K. Zhu, D. Xia and R. Fan, Two-Dimensional Metal-Organic Frameworks-Based Grain Termination Strategy Enables High-Efficiency Perovskite Photovoltaics with Enhanced 
Moisture and Thermal Stability, Adv. Funct. Mater., 2021, 31, 2010368.

51 J. Peng, Y. Sun, Y. Chen, Y. Yao and Z. Liang, Light and Thermally Induced Evolutional Charge Transport in $\mathrm{CH}_{3} \mathrm{NH}_{3} \mathrm{PbI}_{3}$ Perovskite Solar Cells, ACS Energy Lett., 2016, 1, 1000-1006.

52 Y. Liu, H. Zhang, Y. Zhang, B. Xu, L. Liu, G. Chen, C. Im and W. Tian, Influence of Hole Transport Layers on Internal Absorption, Charge Recombination and Collection in HC(NH2)2PbI3 Perovskite Solar Cells, J. Mater. Chem. A, 2018, 6, 7922-7932.

53 W. T. Wang, P. Chen, C. H. Chiang, T. F. Guo, C. G. Wu and S. P. Feng, Synergistic Reinforcement of Built-In Electric Fields for Highly Efficient and Stable Perovskite Photovoltaics, Adv. Funct. Mater., 2020, 30, 1909755.

54 J.-H. Lee, J. Kim, G. Kim, D. Shin, S. Y. Jeong, J. Lee, S. Hong, J. W. Choi, C.-L. Lee, H. Kim, Y. Yi and K. Lee, Introducing Paired Electric Dipole Layers for Efficient and Reproducible
Perovskite Solar Cells, Energy Environ. Sci., 2018, 11, 1742-1751.

55 E. H. Jung, N. J. Jeon, E. Y. Park, C. S. Moon, T. J. Shin, T. Y. Yang, J. H. Noh and J. Seo, Efficient, Stable and Scalable Perovskite Solar Cells Using Poly(3hexylthiophene), Nature, 2019, 567, 511-515.

56 H. Zhang, X. Ren, X. Chen, J. Mao, J. Cheng, Y. Zhao, Y. Liu, J. Milic, W.-J. Yin, M. Grätzel and W. C. H. Choy, Improving the Stability and Performance of Perovskite Solar Cells via Off-the-Shelf Post-Device Ligand Treatment, Energy Environ. Sci., 2018, 11, 2253-2262.

57 S. Wang, B. Yang, J. Han, Z. He, T. Li, Q. Cao, J. Yang, J. Suo, X. Li, Z. Liu, S. Liu, C. Tang and A. Hagfeldt, Polymeric Room-Temperature Molten Salt as a Multifunctional Additive Toward Highly Efficient and Stable Inverted Planar Perovskite Solar Cells, Energy Environ. Sci., 2020, 13, 5068-5079. 